Project ID: $\mathbf{5 4 6 2 8}$

\title{
Colloidal Agglomerates in Tank Sludge: Impact on Waste Processing
}

(First Year of Funding: FY 1996)

\section{Lead Principal Investigator}

Dr. Joel M. Tingey

Pacific Northwest National Laboratory

P.O. Box 999, MSIN P7-25

Richland, WA 99352

(509) 376-2580 (phone)

(509) 372-3861 (fax)

joel.tingey@pnl.gov

\section{Co-Investigators}

Dr. J. A. Martin

Sandia National Laboratories

P.O. Box 5800

Albuquerque, NM 87185

(505) 844-9125 (phone)

(505) 844-4045 (fax)

Professor John D. Berg

University of Washington

Department of Chemical Engineering, BF-10

Seattle, WA 98195

(206) 543-2029 (phone)

(206) 543-3378 (fax) 


\section{Research Objective}

Insoluble colloidal sludges in hazardous waste streams such as tank wastes can pose serious problems for waste processing, interfering with retrieval, transport, separation, and solidification processes. Properties of sediment layers and sludge suspensions such as slurry viscosities, sedimentation rates, and final sediment densities can vary by orders of magnitude depending on the particle types present, the degree to which the particles agglomerate, and processing parameters such as shear rates, $\mathrm{pH}$, salt content, and temperature. The objectives of this research are to

- understand the factors controlling the nature and extent of colloidal agglomeration under expected waste processing conditions

- determine how agglomeration phenomena influence physical properties relevant to waste processing including rheology, sedimentation, and filtration

- develop strategies for optimizing processing conditions via control of agglomeration phenomena.

\section{Problem Statement}

Complex radioactive mixtures of supernatant liquids (typically highly basic salt solutions), saltcake (consisting primarily of sodium nitrate and nitrite), and insoluble sludges consisting of submicron colloidal particles are stored at various locations on U.S. Department of Energy (DOE) sites. Over 100 million gallons of this radioactive waste is stored in underground tanks. The largest quantity and most complex mixtures of these radioactive wastes are located at the Hanford Site. Although the radioactivity is the primary concern in remediating these wastes, handling and processing the radioactive insoluble sludges provides a major technical challenge. Treatment and ultimate disposal of these wastes will require that these insoluble sludges be dispersed in aqueous solutions for retrieval and transport, separated from the liquid, and converted to a stable waste form. These tank wastes will be partitioned into highlevel and low-level fractions because of the high cost of high-level waste vitrification and geologic disposal. The low-level fraction will be processed to remove ${ }^{137} \mathrm{Cs}$ (and possibly other radionuclides) and will then be immobilized in a glass matrix and disposed of by shallow burial on site. The high-level fraction will be immobilized in a borosilicate glass matrix, and the resulting glass canisters will be disposed of in a geologic repository. The maximum possible solids loading in each of the processing steps and the final waste forms are desired to minimize waste volumes.

The ability to maximize the solids loading and effectively process the wastes is dependent upon understanding and properly manipulating the colloidal behavior in these waste streams. Depending on processing conditions, these colloidal particles can form agglomerated networks having high viscosities that could clog transfer lines or produce high volumes of low-density sediments that interfere with solidliquid separations such as settle-decant operations during sludge washing and leaching. Under different conditions, the particles can be dispersed to form very fine suspended particles that do not settle during settle-decant operations. These suspended particles may foul and contaminate downstream components such as ion exchangers or filtration systems. The formation and properties of viscous sludge layers also contribute significantly to the retention and periodic release of potentially flammable or explosive gas mixtures in some Hanford tanks. Colloidal agglomerates are also important to the processing and remediation of other waste streams, including the sludges present in fuel storage basins such as the K-Basins at Hanford. 
Given the wide range of waste chemistries present at Hanford and other DOE sites, it is impractical to measure the properties of all possible sludge compositions under all potential processing conditions to design effective treatment procedures. Instead, a framework needs to be established to predict sludge property trends on a sound scientific basis. The underlying principles of colloid chemistry and physics provide such a framework, allowing us to predict and eventually control the physical properties of sludge suspensions and sediment layers in tank wastes and other waste processing streams.

\section{Research Progress and Implications}

This research project combines experimental and theoretical efforts to determine the impact of colloidal agglomeration on tank waste processing. Components of this research program include 1) understanding the nature of the primary particles and agglomerates that comprise tank sludge, 2) determining how particle and agglomerate distributions influence the physical properties of sludge, 3) understanding the critical interparticle interactions that control agglomerate distributions and slurry properties, and 4) developing chemical and physical methods to deliberately manipulate agglomerate structures during different waste processing steps. Work on the first two items was largely completed in FY 1997 and FY 1998. Work is in progress to understand how interparticle interactions influence agglomeration and sludge properties. A summary of the progress on items 1 and 2 is provided in this report, but the majority of the report will address items 3 and 4.

\section{Particles and Agglomerates in Actual Tank Sludge}

Work done prior to this year demonstrated that Hanford sludges consist largely of submicron $\left(<10^{-6} \mathrm{~m}\right)$ primary particles of hydrated oxides of $\mathrm{Al}, \mathrm{Fe}, \mathrm{U}, \mathrm{Zr}, \mathrm{Mn}, \mathrm{Cr}, \mathrm{Ni}$, and Ti. Small particles of insoluble salts such as apatite $\mathrm{Ca}_{5}\left(\mathrm{PO}_{4}\right)_{3} \mathrm{OH}$, uranium phosphate, aluminum phosphate, bismuth phosphate, and the zeolite cancrinite are also present. In existing tanks, and in most proposed tank processing schemes, the particles are in contact with highly basic (pH 10-14), high ionic strength (0.1-10 M) salt solutions (mainly $\mathrm{NaNO}_{3}$ and $\mathrm{NaOH}$ ). In such solutions, the electrical double layers associated with charged sites in particle surfaces collapse, and the electrostatic repulsions that can disperse particles of like charge disappear. Therefore, under most tank waste processing conditions, the particles comprising most sludges are predicted to be attracted to each other (van der Waals attraction dominates) resulting in extensive particle agglomeration. Most of the work performed in this project involves examining model suspensions containing mixtures of one or two of the major components found in actual wastes and studying how agglomeration influences physical properties such as viscosity and sedimentation. Experimental results on the simple systems are rationalized using theoretical models that describe particulate suspensions. Property models developed from theory and experiment on the simple suspensions are then applied to explain the limited results that have been obtained on actual tank wastes.

Rheological and physical data have been obtained on samples from 17 single-shell and 10 doubleshell tanks. Many of these samples were processed to simulate the baseline processes proposed for ultimate disposal of these tank wastes. Physical properties and rheology have also been measured on these process samples. The results from these analyses have been compared with the results obtained on the simple systems used in this project. Large variability is observed in the properties of the waste in the tanks. This variability is also observed within an individual tank. In spite of this variability, the experimental results obtained for simple surrogate systems are comparable to actual tank waste samples under similar conditions. 
The capabilities developed in this project have been used in obtaining more detailed physical properties on actual tank waste sludges and other radioactive waste samples such as K-Basin sludges. Extensive particle size distribution, sedimentation behavior, and particle density data have been obtained on samples from Hanford tanks 241-AW-101, 241-AN-107, and 241-AN-105 using the equipment and knowledge obtained in this project. Significant processing issues of the K-Basin sludges have been resolved based on data obtained and understood because of the research efforts associated with this project. Particle size distribution of samples obtained from the gunite tanks at ORNL is currently being considered at PNNL using these capabilities.

\section{Agglomerate Structures: Impact on Sludge Properties}

The properties of agglomerated sludges are dominated by the properties of the agglomerates, which are fractal objects whose mass scales as $\mathrm{R}^{\mathrm{D}}$, where $\mathrm{R}$ is the agglomerate size and $\mathrm{D}$ is the fractal dimension. For a diffusion-limited aggregate, $\mathrm{D}=1.8 ; \mathrm{D}=3.0$ for a dense three-dimensional object. Fractal agglomerates can have an enormous impact on slurry properties because they have lower densities and occupy much more space than dense particles at the same solids loading. The solids loading within an individual agglomerate, $\Phi \mathrm{a}$, is given by the expression $\Phi \mathrm{a}=(\mathrm{R} / \mathrm{r})^{\mathrm{D}-3}$, where $\mathrm{r}$ is the primary particle size. As shown in Figure 1, Фa can vary over three orders of magnitude depending on the ratio of the agglomerate size to the primary particle size and the fractal dimension. When agglomerates fill the solution and begin to contact each other (at a solids loading referred to as the percolation threshold or gel point $(\Phi \mathrm{g}=0.17 \Phi \mathrm{a})$, slurry viscosities can increase by orders of magnitude. Sediment densities are usually not much greater than $\Phi \mathrm{g}$ because sedimentation rates are slow to negligible above the gel point. Work on this project has shown that fairly accurate values for $\Phi \mathrm{g}$ can be calculated for both single component slurries and actual tank wastes if $\mathrm{r}, \mathrm{R}$, and $\mathrm{D}$ are determined experimentally.

For this program, primary particle size distributions have been determined using transmission electron microscopy, and agglomerate size distributions have been estimated using static light scattering on dilute suspensions. Direct measurements of the fractal dimension D have not been made, but based on literature studies on model systems, $\mathrm{D}=2.2$ has been used to model slurry properties (the theoretical value for a

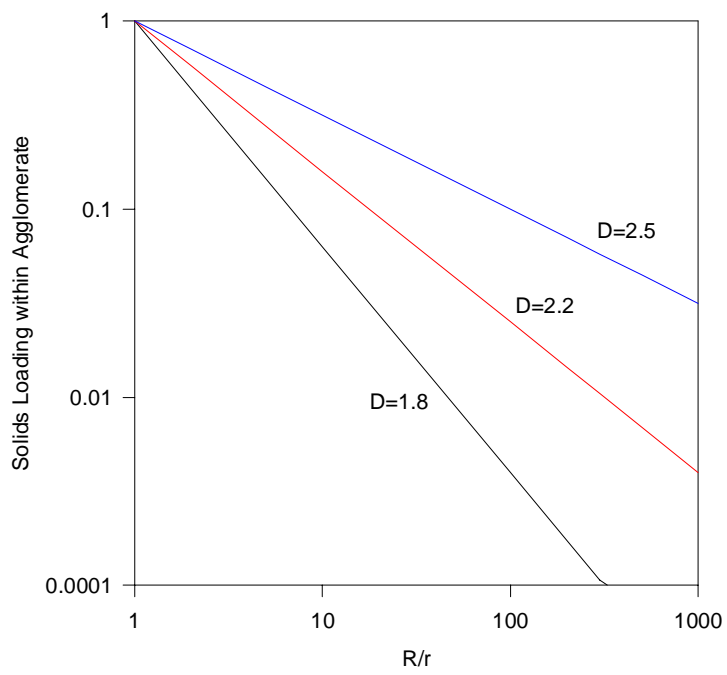

Figure 1. Solids Loading Within Fractal Agglomerates as a Function of R/r and D 
rearranged reaction-limited aggregate). Using experimental $\mathrm{r}$ and $\mathrm{R}$ values and $\mathrm{D}=2.2$, sediment densities have been predicted to within about $20 \%$ for single component systems as well as actual sludges, solids loadings at which slurry viscosities will exceed the desired maximum of around $100 \mathrm{cP}$ have been predicted to within about $30 \%$, and sedimentation velocities in settle-decant operations have been predicted to within a factor of around 5. In terms of general trends, the least tractable slurries are those containing the smallest primary particles (10 nm particles are common in actual tank sludges), the largest agglomerate sizes, and the smallest fractal dimensions. Such slurries can have viscosities in excess of $10,000 \mathrm{cP}$ at solids loadings as low as $1 \mathrm{vol} \%$, which corresponds to the lowest sediment densities. At the other extreme, slurries containing primary particles larger than $10 \bullet \mathrm{m}$ can exhibit viscosities below $100 \mathrm{cP}$ even at $30 \mathrm{vol} \%$ and pack to form dense sediments having solids loadings that exceed $35 \mathrm{vol} \%$. Of the 20 or so distinct Hanford wastes examined to date, most exhibit gel points from 1-8 vol\%. For the finest sludges, dilution factors as high as 20 may be required to keep from plugging pipes and transfer lines with viscous colloidal gels, generating millions of gallons of additional waste requiring treatment and ultimate disposal.

\section{Interparticle Interactions: Impact on Sediment Densities}

The focus of research during FY 1998 and FY 1999 has been on achieving an understanding of the relationships between interaction potentials and sediment densities in the high-salt, high-pH regime representative of most tank wastes. Work done prior to FY 1998 showed that changes in salt content representative of sludge washing and leaching operations can change sediment volumes by as much as a factor of two, having an enormous impact on processing tank utilization and separation efficiencies. Our practical goal is to be able to predict and control sediment densities in basic salt solutions. This regime is also of significant scientific interest because interaction potentials in such solutions cannot be described using classical electrical double-layer theory (the double layers collapse in high ionic strength solutions).

The macroscopic physical properties for a particular colloidal particle gel depend on both the gel microstructure and the interparticle forces. One example of a gel property is the compressive yield stress, $\mathrm{P}_{\mathrm{y}}(\phi)$, which is a measure of the force required to compact a gel network to a specified volume fraction, $\phi$. The compressive yield stress controls both the final sediment height of a colloidal suspension and the rate at which the sediment compresses to reach that final height. A model has been developed to calculate the compressive yield stress as a function of gel microstructure and interparticle forces using the Brownian dynamics simulation method.

In this model, the initial particle network configuration was created using Brownian dynamics. A random distribution of noninteracting particles is formed using a series of Monte Carlo moves. Brownian motion then moves the individual particles or particle clusters until contact is made with another particle or cluster. The two are then combined to form a rigid cluster, which then has translational and rotational diffusion based on cluster size. This procedure continues until a continuous gel has been formed. The first series of three-dimensional colloidal gel models consisted of 10,000 particles and was created assuming diffusion limited aggregation. Gels were created for 2.0, 4.0, 6.0 and 8.0 vol\%. A sample gel configuration is shown in Figure 2.

Once a gel configuration has been created, the rigid bonds are replaced with an interaction potential, which consists of both a repulsive core potential and a surface-bonding interaction. The core potential is based on the distance between particle centers. The surface-bonding interaction prevents a connecting particle from freely moving around the circumference of its partner, giving the gel its rigidity. The specified potential well depth determines the surface interaction strength. When the surface-point to surface-point distance exceeds a specified value, the connection is broken. If two particles move within the cutoff distance, a new connection is formed. 


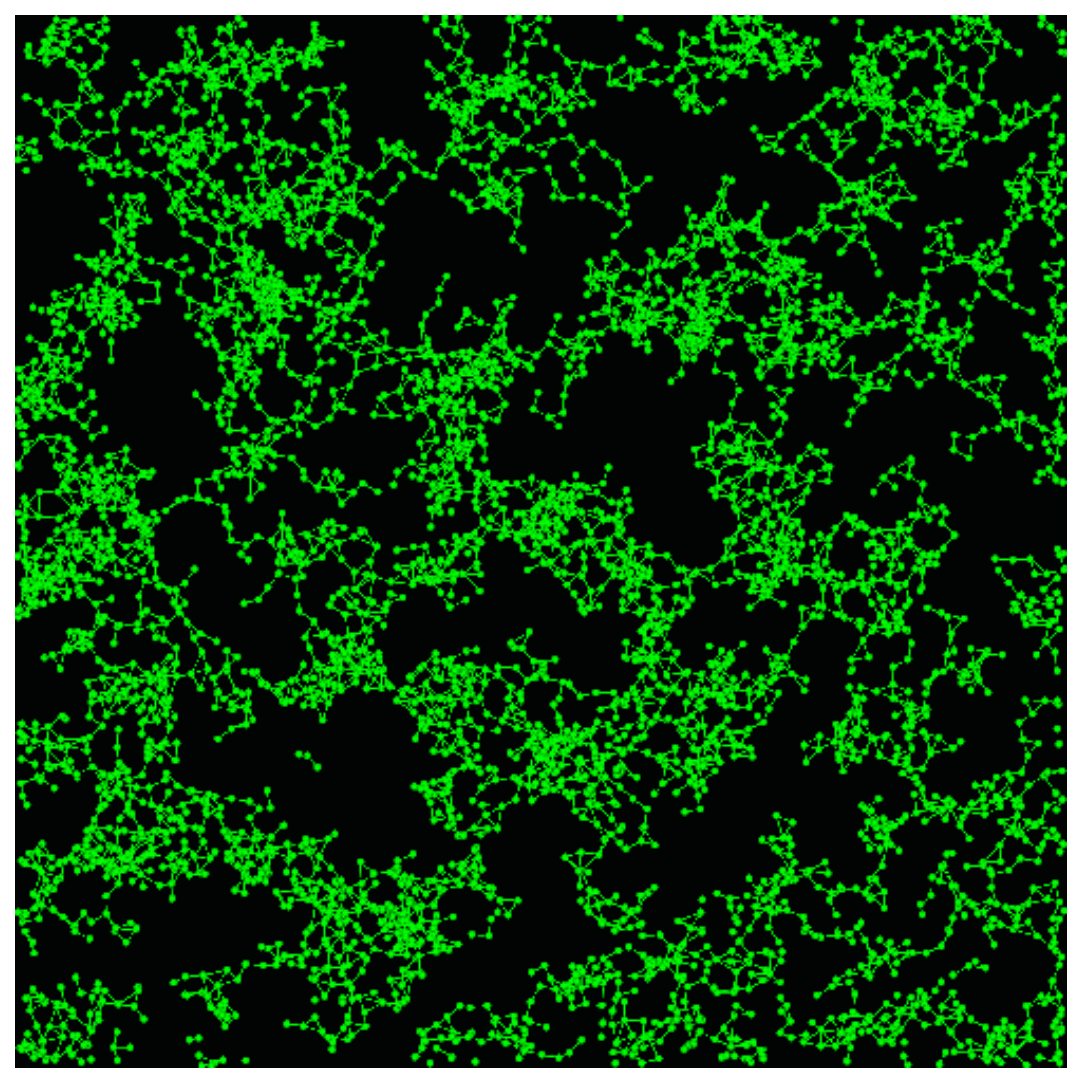

Figure 2. Initial Particle Gel Configuration from Brownian Dynamics Simulation

The compressive yield stress as a function of volume fraction is determined by performing a compression simulation on the gel structure and calculating the resulting stress tensor. The compression simulation is performed using a repeating sequence of two stages, a compression stage and an equilibrium stage. During the compression stage, the scaling factor is gradually reduced in a linear fashion. The rate of reduction depends on a variety of factors, including the potential well depth and temperature. During this stage, interparticle connections are broken and new ones are created as the gel network structure changes to accommodate the reduction in volume. After a period of time, the scaling factor is held constant and the system is allowed to reach equilibrium. The approach to equilibrium is monitored using the calculated values of the stress tensor. Once the system has reached equilibrium, quantities such as the stress tensor and the coordination number are calculated for that volume fraction. This procedure is repeated until the volume fraction reaches a specified value. The calculated stress is then plotted as a function of volume fraction. Preliminary results have been obtained for the initial volume fractions listed for a single form of the interparticle potential.

This simulation methodology provides a direct connection between the microscopic interparticle interaction potential, which is not directly measurable, and the macroscopic gel property compressive yield stress, which can be obtained from sedimentation experiments. By varying the interparticle potential and comparing the change in the compressive yield stress with experimental results, we may be able to infer the effect of changes in solution chemistry on the interparticle potential.

Sedimentation experiments were performed at varying solids loadings, $\mathrm{pH}$, salt concentration, salt type, and applied pressure to determine the impact of chemical processing on the sediment densities that can be obtained during settle-decant processes. These results are also being compared with the models 
being developed. Based on these results, it is possible to extract values for the gel point and the compressive yield stress of the sediment (which is a measure of how deformable and compressible the sediment is.) Once these parameters are known, sediment densities can be predicted for a wide range of processing geometries, including extrapolation from lab-scale tests to sedimentation in a one-milliongallon tank.

Sedimentation studies were conducted on $1.3 \mu \mathrm{m}$ primary particles of gibbsite $\left(\mathrm{Al}(\mathrm{OH})_{3}\right)$ suspended in sodium nitrate solutions at different salt concentrations and $\mathrm{pH}$ values. At $\mathrm{pH} 4$ and $0.01 \mathrm{M} \mathrm{NaNO}_{3}$, the primary particles of gibbsite are dispersed. Because the particles are relatively large, they settle within a few days. The dispersed particles pack efficiently as they settle, yielding a sediment with a density of $50 \mathrm{vol} \%$ (the theoretical maximum solids loading for packed spheres is $63 \mathrm{vol} \%$ ). Such a sediment would be ideal for maximizing the efficiency of solid-liquid separations. In contrast, the same gibbsite particles suspended in $0.1 \mathrm{M} \mathrm{NaNO}_{3}$ at $\mathrm{pH} 4$ yield a sediment density of only 4 vol\% solids (consistent with 6-7 $\mu \mathrm{m}$ fractal agglomerates each containing around 30 primary particles). This means that the agglomerated sludge occupies over 10 times more space and contains 24 times the volume of non-removable interstitial liquids than the sediment formed from the dispersed sludge, having an adverse impact on the efficiency of solids-liquids separations. As salt concentrations are increased still farther, to $5 \mathrm{M}$, sediment densities increase to $5.1 \mathrm{vol} \%$, suggesting that "short range" or "hydration" forces associated with adsorbed salt layers might be weakening the interactions between particles. High salt concentrations could also change sediment densities by changing agglomerate structures.

To investigate the role of adsorbed ions on interparticle interactions, systematic variations were made in the cations and anions present in dissolved salts to examine whether specific ions were more effective than others in weakening sediment structures. Gibbsite particles were suspended in aqueous solutions containing various salts $\left(\mathrm{NaNO}_{3}, \mathrm{NaCl}, \mathrm{CsCl}, \mathrm{LiCl}, \mathrm{Mg}\left(\mathrm{NO}_{3}\right)_{2}, \mathrm{CaCl}_{2}\right.$, and $\left.\mathrm{BaCl}_{2}\right)$ as a function of $\mathrm{pH}$ ( $\mathrm{pH} 4-14)$ and salt concentration $\left(10^{-2} \mathrm{M}-5 \mathrm{M}\right)$ (Figure 3). All salts tested promote sediment compression at concentrations above $1 \mathrm{M}$. While anion $\left(\mathrm{Cl}^{-}\right.$for $\left.\mathrm{NO}_{3}^{-}\right)$and cation $\left(\mathrm{Li}^{+}\right.$or $\mathrm{Cs}^{+}$for $\left.\mathrm{Na}^{+}\right)$substitutions have no apparent effect, salts of divalent cations $\left(\mathrm{Mg}^{2+}, \mathrm{Ca}^{2+}, \mathrm{Ba}^{2+}\right)$ all promote sediment compression. Most dramatic is the effect of $\mathrm{CaCl}_{2}$, which yields sediments having solids loading of over $15 \mathrm{vol} \%$ (twice the particle density seen in $\mathrm{NaNO}_{3}$ solutions). The effect is not merely an ionic strength effect, because $\mathrm{BaCl}_{2}: \mathrm{NaCl}$ mixtures having the same ionic strength but different $\mathrm{Ba}: \mathrm{Na}$ show greater compression as the Ba content is increased. The results suggest that heavily hydrated cations can act as "molecular ball bearings," allowing agglomerates to deform and compact. The results represent one example of how it may be possible to use chemical additives to control sludge behavior.

As is shown in Figure 4, $\mathrm{pH}$ has a significant impact on the sediment densities obtained during settledecant operations. The lowest sediment density is observed near the isoelectric point of the particle with the sediment density increasing on either side of the isoelectric point. The isoelectric point of a particle is the $\mathrm{pH}$ value at which a reversal of the charge on the particle is observed electrophoretically. Zeta potential is the potential of the particle at the surface of shear and is related to the electrophoretic mobility of the particle; therefore, a measurement of the zeta potential of a slurry as a function of $\mathrm{pH}$ will provide insight into the impact of $\mathrm{pH}$ on the sediment densities that would be obtained during settle-decant operations.

Zeta potential measurement of colloidal dispersions at high salt concentrations is a new and unexplored scientific area with many reported departures from expected theory, including elimination of the isoelectric point and restabilization of colloidal particles with adsorbed surfactants. 


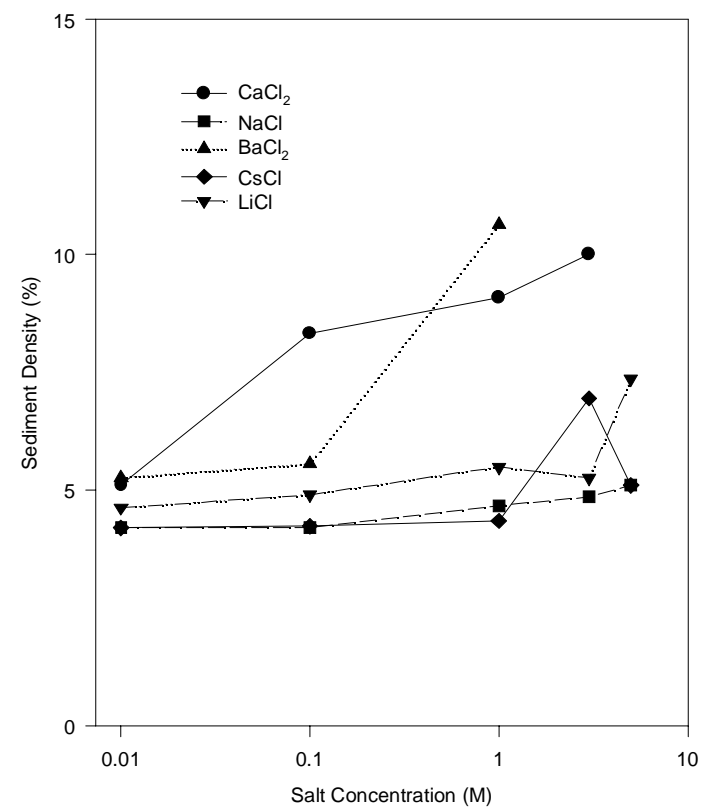

Figure 3. Impact of Salt Concentration and Type on Sediment Density

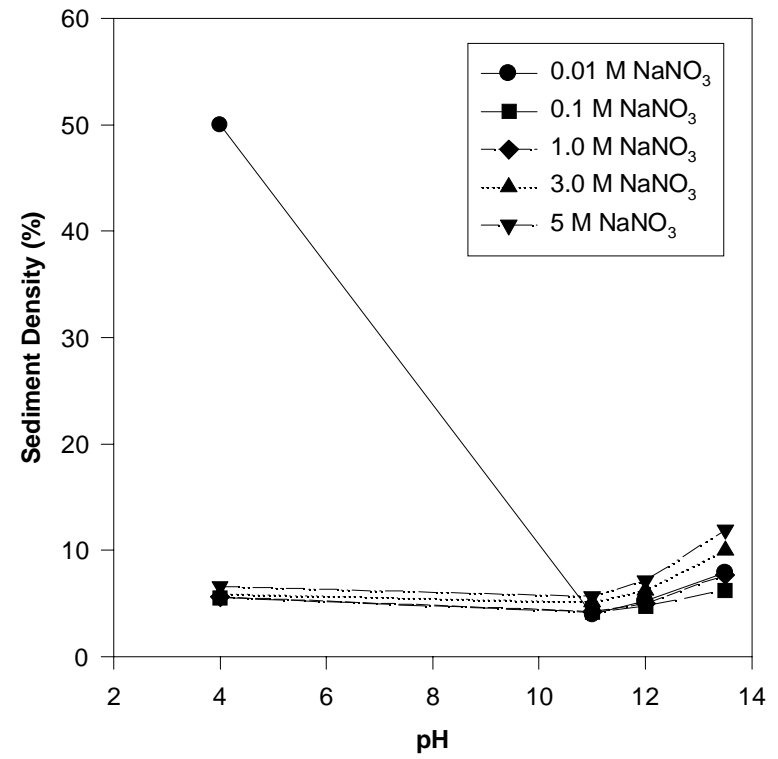

Figure 4. Impact of $\mathrm{pH}$ and Salt Content Salt on Sediment Density

Zeta potential is experimentally determined by measuring the motion of particles in solution under an applied electric field. Traditionally, these measurements are performed at low ionic concentrations due to experimental difficulties at high salt concentrations. The ZetaPals is designed to permit the measurement of zeta potential at high salt concentrations. These measurements are still problematic and require attention to establishing the proper experimental conditions (voltage, frequency, and sample count rate) and expertise combined with common sense in interpreting the results. The high conductivity of the concentrated salt solutions limit the voltage and current that can be applied to the solution while still imparting movement of the particles due to the applied electric field. If too high a voltage is applied, water is broken down to hydrogen and oxygen at the anode and cathode respectively. If too high a current is applied, the sample is heated and fluid-flow gradients are created that disturb the measurement of particle motion.

Over the last several months, the zeta potential of alumina $(0.01 \mathrm{wt} \%)$ in water, $\mathrm{NaNO}_{3}$, and $\mathrm{LiCl}$ has been measured. Zeta potential measurements of alumina in water as a function of $\mathrm{pH}$ compared well with values reported in the literature. Zeta potential measurements of alumina in $\mathrm{NaNO}_{3}$, as a function of $\mathrm{pH}$, at higher salt concentrations were then undertaken. Measurements were made at 0.1, 1.0, 2.0 and 3.0 M $\mathrm{NaNO}_{3}$.

Results suggest that at the lower salt concentration $(<2.0 \mathrm{M})$ double-layer theory is observed. This implies that the double layer has collapsed and that the system rapidly aggregates, forming a loose floc network of particles that exhibit a fast sedimentation time and a large sedimentation volume. Initial zeta potential measurements on alumina at $3.0 \mathrm{M} \mathrm{NaNO}_{3}$ suggest that the particle dispersion is restabilized and that the isolelectic point (point of zero charge) is not present. The particles exhibit a positive zeta potential over the entire $\mathrm{pH}$ range investigated. This implies that the particles do not aggregate into a loose floc network and will exhibit a smaller sedimentation volume. This has been confirmed by previous sedimentation results. 
The implication of this work is that the colloidal properties of tank waste under high salt conditions (greater than $2.0 \mathrm{M}$ ) may not behave as expected. If colloidal tank waste is in fact restabilized under high salt conditions, particle size may be smaller than expected, sedimentation time and volume may be different than expected, and filtration properties may be different.

Work performed on this project at the University of Washington is being directed at understanding how organic molecules called steric stabilizers function in the high salt regime of tank wastes. Once the factors controlling steric stabilization at high ionic strength are understood, it may be possible to manipulate sludge behavior with low concentrations of such organic additives. The polymers used as steric stabilizers were BAB block copolymers of polyethylene oxide B blocks and polypropylene oxide A blocks. The B blocks are the stabilizing moiety, and the A blocks anchor the polymer to the laytex surface. The core particle is a polystyrene latex with sulfate functional groups that allow the polymers to anchor to the core particle.

The impacts of polymer molecular weight, salt concentration, and salt type on steric stabilization were investigated. Increasing the molecular weight of the polymer causes an increase in steric stabilization. A small increase in molecular weight from an 11-monomer-length polymer to a 13monomer-length polymer, showed dramatic increases in stabilization of the particle. This increase may be due to ion binding of the salt in the longer polymer that is not possible in the shorter polymer. Results obtained from the 13-monomer-length polymer indicate that order of stabilization in high ionic strength solutions is $\mathrm{BaCl}_{2}>\mathrm{NaNO}_{3}, \mathrm{LiCl}, \mathrm{NaCl}, \mathrm{KCl}>\mathrm{KSCN}, \mathrm{KNO}_{3}$. X-ray photoelectron spectroscopy (XPS) and RAMAN spectroscopy were performed on this same system in both $\mathrm{KSCN}$ and $\mathrm{BaCl}_{2}$ to understand the processes that cause stabilization to occur in $\mathrm{BaCl}_{2}$ and not in KSCN solutions. The results from these studies indicated that the Madelung shift (a constant representing the sum of the mutual potential coulombic attraction energy of all the ions in a lattice) correlates with the order in which the anions induce restabilization of these particles. It was also observed that $\mathrm{BaCl}_{2}$ tends to weaken the ether oxygen bonds in the polyethylene oxide more than the $\mathrm{KSCN}$, but the conformation of the polyethylene oxide is the same in both the $\mathrm{KSCN}$ and $\mathrm{BaCl}_{2}$ solutions.

\section{Planned Activities}

Several key studies are in progress and will be completed before the end of FY 1999. These studies include a comparison of the actual waste rheology and sedimentation with the simple model systems, measurement of short-range forces, and modeling of agglomerate properties.

A report compiling the rheology data that has been collected on actual wastes and comparing these results with the data obtained by simple model systems will be prepared. This report will provide the basis for further improvements in rheological measurement of actual tank wastes.

Now that a simulation methodology has been established for predicting compressive yield stress based on gel structure and interparticle potentials, a parametric study will be performed to determine the effect of changes in the interparticle potential on the compressive yield stress behavior of a sediment. This information will be used to infer the effect of solution chemistry on the interparticle potential by comparing simulation results with experimentally determined compressive yield stress values.

Samples of the polystyrene latex particles with steric stabilizers attached have been submitted to NIST for surface force measurements. These measurements will be used to determine the magnitude of the short-range hydration forces in high ionic strength solutions. Samples have also been submitted for 
nuclear magnetic resonance analysis to better understand ion binding in these model systems.

Equilibrium dialysis, solvent extraction or specific ion electrode analysis will also be performed to quantitate the extent of ion binding.

\section{Publication}

Bunker BC, J Liu, DR Rector, GL Graff, PA Smith, PJ Bruinsma, L Song, XS Li, JD Virden, NG Colton, JR Philips, KD Keefer, and JM Tingey. 1999. "Fractal colloidal agglomerates in nuclear tank wastes: Impact on waste properties and processing" (submitted to Radioactive Waste Management in Environmental Restoration).

\section{Presentations}

Tingey JM, PR Bredt, and R Shekarriz. March 1999. "Rheology and settling behavior of Hanford tank wastes and the resulting process streams.” Rheology in Mineral Industry II, Kahuku, Oahu, Hawaii.

Tingey JM, BC Bunker, GL Graff, KD Keefer, AS Lea, and DR Rector. November 1998. “Colloidal agglomerates in tank sludge and their impact on waste processing." Materials Research Society Fall Meeting, Boston.

Tingey JM, GL Graff, and DR Rector. March 1999. "Effect of colloidal aggregation on sedimentation and rheology in highly basic, high ionic strength salt solutions." Rheology in Mineral Industry II, Kahuku, Oahu, Hawaii. 